\title{
Implementing a new mathematics curriculum: Mathematics teachers' beliefs and practices
}

\author{
Ampadu, Ernest $\bowtie$ \\ Richmond University, United Kingdom (ernest.ampadu@ richmond.ac.uk)
}

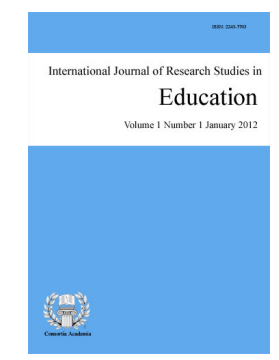

Accepted: 3 November 2013 Online ISSN: $2243-7711$

OPEN ACCESS

\section{Abstract}

Mathematics has become a 'critical filter' in the social, economic and professional development of individuals and forms a core component of the school curriculum in most countries. It is upon this utilitarian nature of mathematics to the individual and the society as a whole that the school mathematics curriculum has been undergoing a number of restructuring over the last three decades. In Ghana, a new mathematics curriculum was introduced in September 2007 which aims at shifting the teaching and learning of mathematics from a teacher-centered approach to more student-centered and participatory teaching and learning. However, since the introduction of the curriculum no study has specifically examined mathematics teachers' teaching practices in relation to these new curriculum requirements. This study examines Junior High School (12-14 years) mathematics teachers' perceived and actual teaching practices in relation to the curriculum requirements. Participants in the study were 41 mathematics teachers' from 22 Junior High Schools. A Semi-structured questionnaire was used to collect quantitative data about teachers' perceived teaching practices, and classroom observation was used to collect qualitative data about actual classroom practices. The key findings include: teachers' espoused the belief that their teaching practices are consistent with the principles and guidelines of the new mathematics curriculum. Teachers' perceived teaching practices were not fully consistent with their actual practices. The movement towards a more constructivist approach as outlined in the curriculum was not fully evident in most of the classrooms observed.

Keywords: mathematics curriculum; teachers; beliefs; teaching and learning; constructivism 


\section{Implementing a new mathematics curriculum: Mathematics teachers' beliefs and practices}

\section{Introduction}

Over the last three decades, the school mathematics curriculum, the teaching and learning of the subject, have become critical issues in most countries. In view of this, the school mathematics curricula have been undergoing numerous changes and the evolution of these new school curricula and methods are designed to find ways to empower students to use practical and investigative approaches when learning mathematics (Thomasenia, 2000). For example in the USA, the National Council of Teachers of Mathematics (NCTM) Agenda for Action in 1980, which was documented in 1989, provided a new wave of change affecting how mathematics should be taught and learned in schools. In this agenda, it was noted that there was the need to pay particular attention to how mathematics is taught instead of concentrating on what mathematics was taught in schools (NCTM, 1989).

The purpose of this agenda was to increase students' participation and engagement in the teaching-learning process by decreasing memorisation of algorithms and reducing teachers' power of being the disseminators of knowledge to their becoming facilitators in the teaching-learning process (NCTM, 1991). Similarly, according to Liu and $\mathrm{Li}$ (2010) the Chinese school mathematics curricula experienced dramatic changes in the late 1990's and the changes included "many different aspects of mathematics education ranging from what is valued for all students to learn, how mathematics should be taught and learned, and how the assessment should be viewed and used" (p. 10). Liu and Li further argued that the purpose of these dramatic changes was to help and motivate students' in learning mathematics through creativity and independent learning which stimulates students' conceptual understanding and interest.

In the United Kingdom, although changes to local curricula, published teaching schemes and the move to a more student-centered approach to teaching and learning started in the 1960s, reforms of mathematics teaching and learning started in the late 1980 with the introduction of a national curriculum and the introduction of new instructional practices (Chambers, 2008). According to Chambers this new school mathematics curriculum was therefore aimed at providing a new mathematics classroom environment that promotes conceptual understanding of mathematical concepts and skills through problem solving. The curriculum aimed at helping students develop their own mathematical skills and competencies with the help of the teacher as a facilitator in the teaching-learning process but not as the custodian of knowledge.

In Ghana, a new mathematics curriculum was introduced and implemented in the year 2007 and aim of this new curriculum was based on the twin premises that all can learn mathematics and that all need to learn mathematics with a view to achieving a curriculum that reflects individual students' needs (Ministry of Education, Science and Sports; MoESS, 2007). The ultimate goal of the current curriculum is to enable all students' acquire the mathematical skills, insight, attitudes and values needed to be successful in their chosen careers and daily lives by increasing the students' self-oriented learning abilities to the maximum. The new curriculum therefore encourages the acquisition of more skills and use of varied teaching methods and resources to help students to develop the mathematical skills that they will need in their daily activities (MoESS, 2007).

The new curriculum also aims at bringing a shift from a teacher-centered approach of teaching and learning to a more participatory teaching and learning methods to help students develop their skills through the application and experimentation of different problem solving skills (MoESS, 2007). The new national mathematics curriculum therefore highlights the importance of students' active role in the teaching-learning process, which represents a shift from a teacher-centered approach to teaching to a student-centered approach. The new curriculum like other school curricula around the world is underpinned by the epistemologies of 
Implementing a new mathematics curriculum: Mathematics teachers' beliefs and practices

constructivism and it advocates for a change in teachers' role as custodian of knowledge to facilitators in the teaching-learning process.

Since the introduction of these new school curricula and their accompanied new teaching and learning strategies, educational researches investigating into the teaching and learning of the mathematics has been increasing tremendously. Investigating into mathematics teachers' beliefs and perceptions about the teaching and learning of mathematics and implementation of these school curricula has been increasing for some time now as teachers' are most often the implementers of these new curricula. Schraw and Olafson (2008) described the individual's epistemological beliefs as the individual's collective beliefs about the origin and acquisition of knowledge. They further added that a mathematics teacher's epistemological beliefs are important for understanding their teaching. According to Hersh (1986) independent of the teaching and learning approaches enshrined in these school mathematics curricula, the individual teacher's beliefs and theoretical viewpoints are very important as one's beliefs of what mathematics is affect one's conception of how it should be taught and learned.

Ernest (1989) opines that "teaching reforms cannot take place unless teachers' deeply hold beliefs about mathematics teaching and learning change consistent with the policy documentation" (p. 249). That is, a change of approach to the teaching of mathematics "depends fundamentally on the teacher's system of beliefs, and the teacher's conception of the nature of mathematics" (Ernest 1994, p.1). Ernest further added that the implementation of a curriculum change will be practically impossible if teachers' beliefs and theoretical perspectives are not taken into consideration in the development of these new curricula.

A lot of researchers (e.g. Ernest, 1989; Jurdak, 1991; Schoenfeld, 2002; Speer, 2005) have investigated into mathematics teachers' beliefs and how these beliefs impact on their teaching. A number of these studies have confirmed that there is a direct relationship between mathematics teachers' beliefs about a new curriculum and the way they teach. For example, Jurdak (1991) in his research on mathematics teachers, reveals that "the conceptions of the foundations of mathematics are more related to teaching behaviors than to self-reported conceptions of mathematics which normally reflect the expectations of what constitutes 'good' teaching" as enshrined in the school curriculum (p. 228). Pepin (1999), in his study of the conception and work of mathematics involving three European countries: England, France and Germany, also shows that teachers' perspectives are reflected in their teaching practices. Similarly, Smith III (1996) explained that teachers' perceptions of their teaching practices have always been in favor of new curriculum principles although their actual teaching practices may vary or may be completely different from the underlining principles of new curriculum.

In Ghana, there has been a significant and developing research (eg. Ampiah et al., 1996; Coffie, 2004; Duedu, 2001; Mereku, 2004; Flecther, 2005; Anamuah-Mensah \& Mereku, 2005; Akyeampong \& Kuroda, 2007; Frempong, 2010; Adetunde, 2007; Anku, 2008) focus on improving mathematics teaching and learning in Ghana for some time now. Much of the research on quality teaching and learning of mathematics (eg Ampiah et al., 1996; Anamua-Mensah \& Mereku 2005; Frempong \& Ayia, 2007) has been conducted away from the classroom which is the main site for teaching and learning. For example, Adetunde (2007) have also looked at improving the teaching and learning of mathematics in second cycle schools in Ghana with particular reference to factors that impede the teaching and learning of mathematics. Others (eg Ampiah et al., 1996; Akwanta, 2004) have also examined teachers and students attitudes towards mathematics as well as the issue of teacher development and training. In addition to this, Asiedu-Addo (2004) has also examined mathematics teachers' knowledge of the subject content and methodology. Mereku (2003), Eshun (2004), and Eshun-Famiyeh (2005) have investigated also into mathematics classroom practices at the primary and senior secondary levels, however, very little is known about teaching and learning at the junior secondary level which is the transition point between the primary and senior secondary levels. In addition to this, much of the research on the teaching and learning of mathematics (eg Ampiah et al., 1996; Anamua-Mensah \& Mereku, 2005; Frempong \& Ayia, 2007) has been conducted away from the classroom which is the main site for teaching and learning. 
Ampadu, E.

Although, many of these studies have provided some insight into understanding how mathematics teachers' beliefs shape their teaching and implementation of a new mathematics curriculum, very little is known about the situation in Ghana. The main purpose of this present study is to provide an in-depth analysis of Ghanaian Junior High School mathematics teachers' beliefs and examine if there is any relationship between these beliefs and the way teachers' implement this new mathematics curriculum. More specifically, the present study aims at finding answers to the following research questions:

1. What are mathematics teachers' beliefs about their teaching?

2. Are there any differences between mathematics teachers' teaching beliefs and the curriculum requirements?

3. Is there any relationship between mathematics teachers' beliefs and the way they teach?

As indicated above, the teaching and learning of mathematics has become a major concern in almost all countries around the world and the assessment of Ghanaian students have illuminated students poor academic achievements in mathematics (Anamuah-Mensah \& Mereku, 2005). This study is therefore significant in many ways. Firstly, the results and findings from the study will provide useful information regarding mathematics teachers' teaching practices in relation to the specifications of the new mathematics curriculum. This will in turn help policy makers as to how mathematics teachers implement the instructional practices and policies outlined in the new curriculum. Secondly, the conclusion from the study will provide valuable insights for enhancing effective future curriculum restructuring, improving the teaching and learning of mathematics and the way forward for quality mathematics education. The results and conclusions will contribute to the existing literature by providing information on how mathematics is taught and learnt in Ghana from multiple perspectives (using both quantitative and qualitative data) which most research works fail to do.

\section{Methods}

\subsection{Research Design}

The present study is an exploratory study which employed a mixed methods design to provide and in-depth understanding of the problem under consideration. The study combined quantitative and qualitative research methods, data collection and analysis procedures in finding answers to the different research questions. Combining the quantitative and qualitative data collection and analysis procedures will help in providing a better understanding of the research problem and the research questions than using a single approach as proposed by Creswell and Clark (2007).

\subsection{Participants and Sampling Procedure}

The sample for the present study consists of 41 mathematics teachers' from 22 Junior Secondary Schools (JHS) in the Cape Coast Metropolis of Ghana. The sample was drawn from the 72 JHS schools in six educational circuits in the Metropolis. Four schools (totaling 24 schools) were randomly selected from each educational circuit for the purpose of the research. However, two schools decided to withdraw from the study during the data collection process as the teachers were engaged in series of staff training programs during that time. The 41 mathematics teachers in these schools took part in the first phase of the study by completing a semi-structured questionnaire.

During the second phase of the study six of the 22 schools who took part in the study were selected for classroom observation. Each of the 41 teachers' was asked to indicate in the questionnaire whether they would like to take part in the second phase of the study which involved classroom observations. The 30 teachers' from 12 schools who indicated their willingness to take part in the second phase of the study were placed in two groups of six (rural and urban schools) and two schools each (four in total) were selected for collecting the 
qualitative data.

\subsection{Instruments}

The instruments used for the data collection were a semi-structured questionnaire and non-participant observation. The questionnaire had 34 questions and this was divided into four sections: demographic information, teacher's teaching priorities, teaching methods and perceived classroom practices. Since the purpose of the observation was to complement the data from the questionnaire, the observational protocol used was developed in cognizance of the questions in the questionnaires. The first section was used for eliciting background information (school name and school type, teacher's gender, number of students, topic and class level) and the second section was used for collecting data about the lesson design and implementation with emphasis on the teaching methods used (e.g. lecture method, activity method, demonstration method, group work and discovery method). The third section was used for gathering information on students' participation, interaction and learning experiences in the lesson. The use of these two instruments enhanced the internal validity of the research process as the used of the different methods helped in minimizing the limitations posed by one particular method. In addition to this, in order to enhance the reliability of the research instruments, the questionnaire was piloted with some 10 mathematics teachers and the feedbacks received were used to reframe the questions. In addition to this, the reliability of the questionnaire was calculated using the Cronbach Alpha reliability coefficient. The reliability coefficient was found to be 0.75 and the instrument was considered to be reliable, as it exceeded the Cronbach Alpha reliability threshold of 0.7 (Huck 2000).

\subsection{Data Collection and Analysis}

The data collection process was in two stages: In stage one the participants completed the survey questionnaire and in the second stage 10 lessons were observed in the four case study schools. It was anticipated that researcher would observe 12 lessons, that is, three in each school (one each for the three levels; JHS1-3) in the four selected schools with each lesson lasting for 35 minutes, which is the duration of a period in Ghanaian junior secondary schools. However, one of the four case study schools had only two classes (JHS 1 and 2) and in another school the two mathematics teachers agreed to be observed once only, so the actual number of observations was 10 instead of 12 .

\subsection{Data Analysis Procedures}

The two data sets were analyzed separately. The quantitative data from the survey questionnaire was analyzed using the Statistical Package for Social Sciences (SPSS 20.0) and Origin software. Descriptive Uni-variate (involving a single variable) and Bivariate (involving two variables) analysis procedures were used to describe the characteristics of the data collected using absolute numbers and simple percentage to get a general overview of the respondents' responses. In the analysis of the teachers' degree of consensus regarding their teaching and learning practices, a minimum of $70 \%$ was chosen to describe the degree of agreement or disagreement. Results were recorded as statistically significant if the $P$ value was $<0.05$ using the Mann-Whitney U-test. The Mann-Whitney U-test was considered appropriate as the data from the survey was measured using nominal and ordinal scales.

The qualitative data from the classroom observations was transcribed and common themes were identified. To facilitate the comparison process, between the two data sets, the qualitative data from the four case study schools were analyzed using themes and categories used in analyzing the quantitative data. The analysis of the classroom observation data started with transcription of the data and an individual coding system was developed for each lesson and the pre-determined codes and themes used were the instructional practices used, interactions and participation, and resources. The instructional practices codes used were the different teaching methods listed above, and in relation to interactions, teacher talk, and students talk were used to examine how the teacher interacted with the students. Active and passive participation were the codes used in examining students' 
Ampadu, E.

participation in the teaching-learning process. Individual reports for each observed lesson were produced in order to identify common themes for categorization. After this a cross-case analysis of the individual data set from the four case study schools was performed and the summaries of the individual observation reports were analyzed using the inductive analysis procedure, which focuses on searching for patterns and meaning in the data collected to build a general picture of the situation in the observed mathematics classrooms (Hatch, 2002; Kislenko, 2005).

\section{Results}

\subsection{Research Question 1: What are mathematics teachers' beliefs about their teaching?}

To find answers to this research question, the 41 mathematics teachers were asked to rank the perceptions and beliefs of 14 items. A minimum of $70 \%$ was chosen to describe the degree of agreement or disagreement which is the total number of participants that "strongly agree or agree" to a statement.

\section{Table 1}

Teachers' Reported Practices $(N=41)$

\begin{tabular}{lll}
\hline Statements & Percent & Type \\
\hline I start each topic by reviewing students' related knowledge & 100 & Agree \\
I explain things carefully to prevent students from making mistakes & 100 & Agree \\
I go through a variety of methods when solving questions & 95 & Agree \\
I give students the procedures to follow & 100 & Agree \\
I use different teaching approaches when teaching & 98 & Agree \\
I use other textbooks and reference materials & 98 & Agree \\
I encourage students to use the method I teach them & 83 & Agree \\
I ask students to complete easy tasks before attempting difficult ones & 90 & Agree \\
I use the national curriculum recommended teaching methods & 93 & Agree \\
I ask students to work in small groups & 93 & Agree \\
I draw links between topics and move back and forth between topics & 88 & Agree \\
I encourage students to develop their own methods of solving problems & 73 & Agree \\
I tell students which questions to do & 61 & $*$ \\
I teach each topic assuming my students know nothing & 61 & $*$
\end{tabular}

Note. * Means participants neither agreed nor disagreed to the statement as per the chosen percentage

Table 1 show that all the teachers who participated in the study acknowledge the importance of the individual student's prior knowledge in the teaching-learning process. In addition to this, the results show that in as much as teachers tried to use the national curriculum recommended textbooks and teaching methods, the majority of the respondents do not solely rely only on these textbooks and teaching methods but looked for different reference materials, textbooks and different teaching methods. This is consistent with the national curriculum guidelines which entreat teachers to be proactive and innovative in their teaching and use different teaching methods and introduce students to different ways of solving mathematical problems. It was however, interesting to note that 27 percent of the respondents indicated that they do not encourage their students to develop their own methods of solving problems which is not part of the principles of the new curriculum. This is result is contrary to the assertion of Smith III (1996) that teachers' beliefs and perceptions of their teaching practices have always been in favor of new curriculum.

\subsection{Research Question 2: Is there any relationship between teachers' teaching beliefs and the curriculum requirements?}

In order to understand whether there is any significant difference between mathematics teachers' teaching beliefs and the curriculum requirements, the teachers' were asked to indicate the extent to which they agree or disagree with a constructivist view of teaching and learning and behaviorist view of teaching and learning using a four point based Likert scale (1- strongly disagree, 2- disagree, 3-agree and 4- strongly agree). To avoid any response bias from the respondents all the statements used for measuring the teachers' perceptions of their 
teaching practices were positively worded.

\section{Table 2}

Descriptive Statistics of Teachers' Perceptions of their Teaching

\begin{tabular}{|c|c|c|c|}
\hline Climate & Statements & Percent & Type \\
\hline \multirow{8}{*}{ 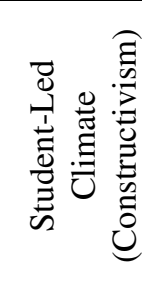 } & I start each topic by reviewing students' related knowledge & 100 & Agree \\
\hline & I go through a variety of methods when solving questions & 95 & Agree \\
\hline & I use different teaching approaches when teaching & 98 & Agree \\
\hline & I use other textbooks and reference materials & 98 & Agree \\
\hline & Students compare different methods of solving a question & 73 & Agree \\
\hline & I ask students to work in small groups & 93 & Agree \\
\hline & I draw links between topics and move back and forth between topics & 88 & Agree \\
\hline & Students develop their own methods of solving problems & 95 & Agree \\
\hline \multirow{8}{*}{ 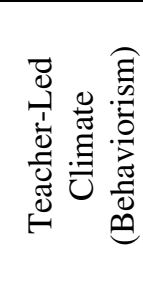 } & I explain things carefully to prevent students from making mistakes & 100 & Agree \\
\hline & I give students the procedures to follow & 100 & Agree \\
\hline & I encourage students to use the method I teach them & 83 & Agree \\
\hline & I encourage students to work on their own & 98 & Agree \\
\hline & I ask students to complete easy tasks before attempting difficult ones & 90 & Agree \\
\hline & I tell students which questions to do & 61 & Agree \\
\hline & I teach each topic from the beginning assuming my students know nothing & 61 & * \\
\hline & I go through one particular method in solving each question & 41 & $*$ \\
\hline
\end{tabular}

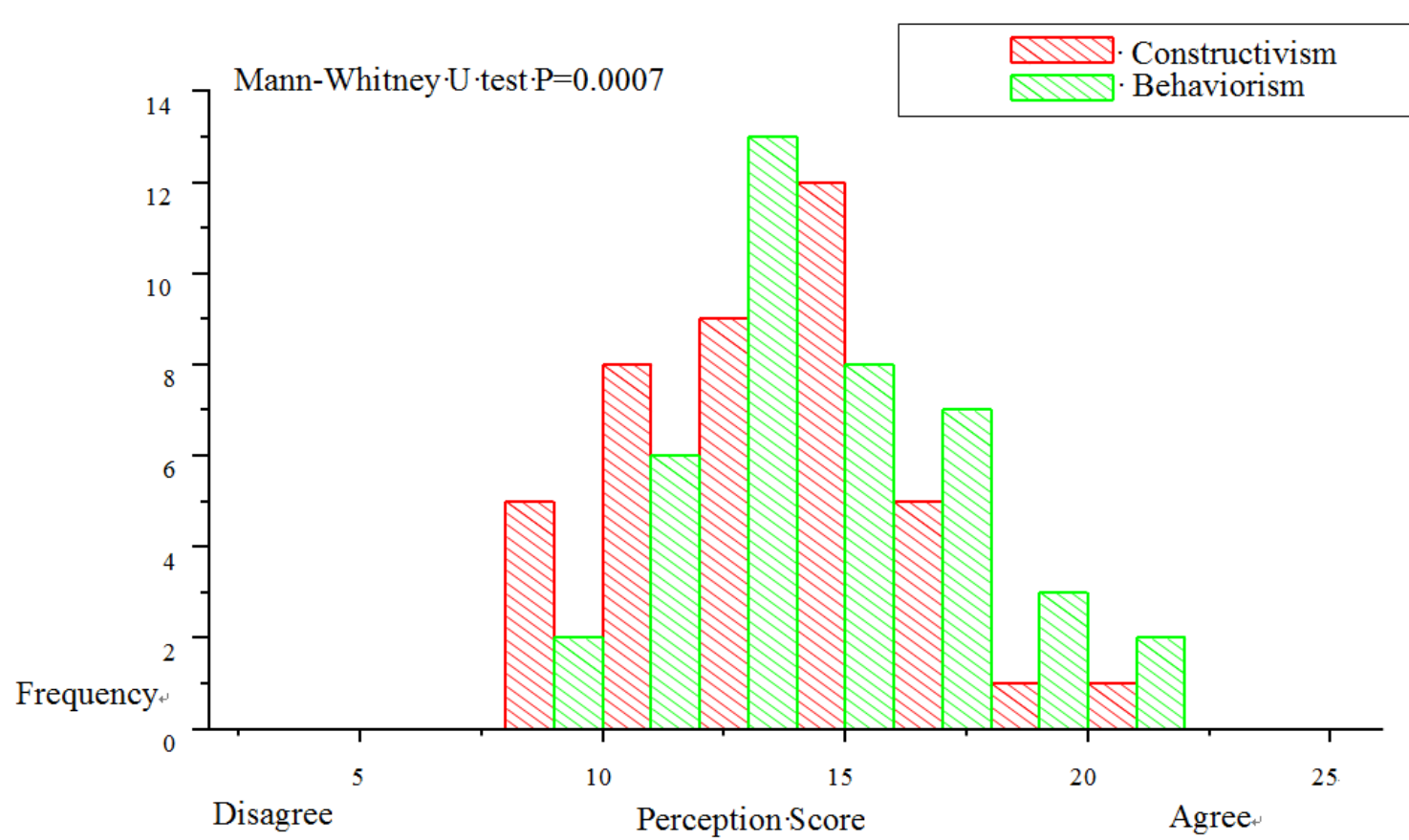

Figure 1. Teachers' Perception of the Teaching

From table 2, the consensus agreement showed a more positive approach or perception toward constructivism. The teachers' showed a more positive consensus to statements relating to instructional practices that aim at helping students to understand the mathematical concept that they are introduced to. Their agreement to statements that help students to be innovative, creative and flexible in their thinking and learning although positive was lower than those of helping students to understand the concept. For example, all the teachers indicated that they review their students' knowledge and use variety of teaching methods in their teaching, however, 93 percent and 73 percent indicated that they encourage students to work in small groups and compare different methods of solving a question respectively. It was also interesting to note all the participants indicated that it is important that students follow routine instructions from the teacher and remembering the procedure that they have to follow in solving mathematical problems. 
Ampadu, E.

To ascertain whether there is any statistical difference between teachers' perceptions of their teaching practices in relation to constructivism and behaviorism, the questions in each category were aggregated to give an overall score of each teacher. This gave a score of constructivist or behaviorist attitude of between 5 and 25, 25 being the highest (see figure 1). The results of statistical test (Mann-Whitley $U$ test, $P=0.0007$ ) shows that there is a statistical difference between teachers perception of their teaching in relation to constructivist and behaviourist teaching practices. That is teachers' beliefs about mathematics teaching conform to the principles of the new mathematics curriculum which is underpinned by the principles of constructivism. However, it can be argued that in as much as the teachers' acknowledge the importance of student-centered approach to teaching, it is also clear that teachers' perception of their teaching practices is a complex one as they hold different views about the teaching and learning of mathematics. That is, although majority of the teachers hold a constructivist view about mathematics teaching, which is consistent with the national curriculum requirements, majority of these teachers also consider the behaviorist approach to the teaching of mathematics as equally important.

\subsection{Research Question 3: Is there any relationship between mathematics teachers' beliefs and the way they teach?}

In answering this research question, the quantitative data from the survey questionnaire was compared with the qualitative data from the classroom observations. Table 4, summarizes the quantitative and qualitative results from the four case study schools. The key indicators in the classroom observation data were rated using a three coding scale ( $1=$ occurred in most parts of the lesson; $2=$ occurred sometimes and $3=$ never occurred). In the table, each plus sign represents a positive response (the teacher perceived or used a particular method or approach). Each minus sign represents a negative response (the teacher perceived or does not use a particular method or approach) and the asterisk sign indicates both positive and negative responses. The colour white was used to represent activities that occurred in most parts of the lesson, light gray for activities that occurred sometimes and dark grey color was used to represent activities that never occurred. The summaries of teachers' beliefs or perceptions of their teaching practices (quantitative (Qt) data from the teachers' questionnaire) and what they actually do (qualitative (Q1) data from the classroom observations) are presented below.

Table 3 shows that there is some consistency between teachers' perception of their teaching and what they actually teach, although there are some inconsistencies. For example, all the teachers' indicated in the questionnaire that, they start their lessons by reviewing students' related knowledge. The analysis of the classroom observation reports revealed that there was a direct relationship between teachers' reported perception of how they start their lessons and observed teaching practices. However, it was interesting to note that what the teachers' considered as review of students' related knowledge was the review of some selected students' knowledge. During the observation, it was established that, in all lessons the reviewing of students' related knowledge targeted at few students and not the whole class. The responses from these few students' who knew the answers to the teacher's questions were used as the related knowledge of the whole class. The perceived review of the related knowledge did not really represent the related knowledge of the whole class but that of some few students who knew the answers to the teacher's questions. The possible implication of this approach was that, in most of the lessons observed it was the same group of people who answered most of the questions asked by the teacher. In most of the lessons observed, the teachers tried as much as possible to actively involve the students in the teaching-learning process through questioning and by so doing concentrated on the few students who knew the answer to the questions.

It is also evident from table 3 that majority of the teachers indicated in the questionnaire that they use combination of different teaching method. The analysis of the classroom observation data however, revealed that although the teachers' used combination of different methods of teaching, the use of these different methods were limited to demonstration and lecture methods and sometimes activity method. From questionnaire, it was clear that the purpose of using different teaching methods was to get the students' involved in the teaching-learning process and also cater for individual student's needs. However, since students' participation in 
the teaching-learning process was through the answering of the teacher's questions in most cases, and this was targeted on some few students, the teachers' end up directing most of the activities to these few students with majority of the students listening and copying notes from the board.

\section{Table 3}

Teachers' Reported and Observed Teaching Practices

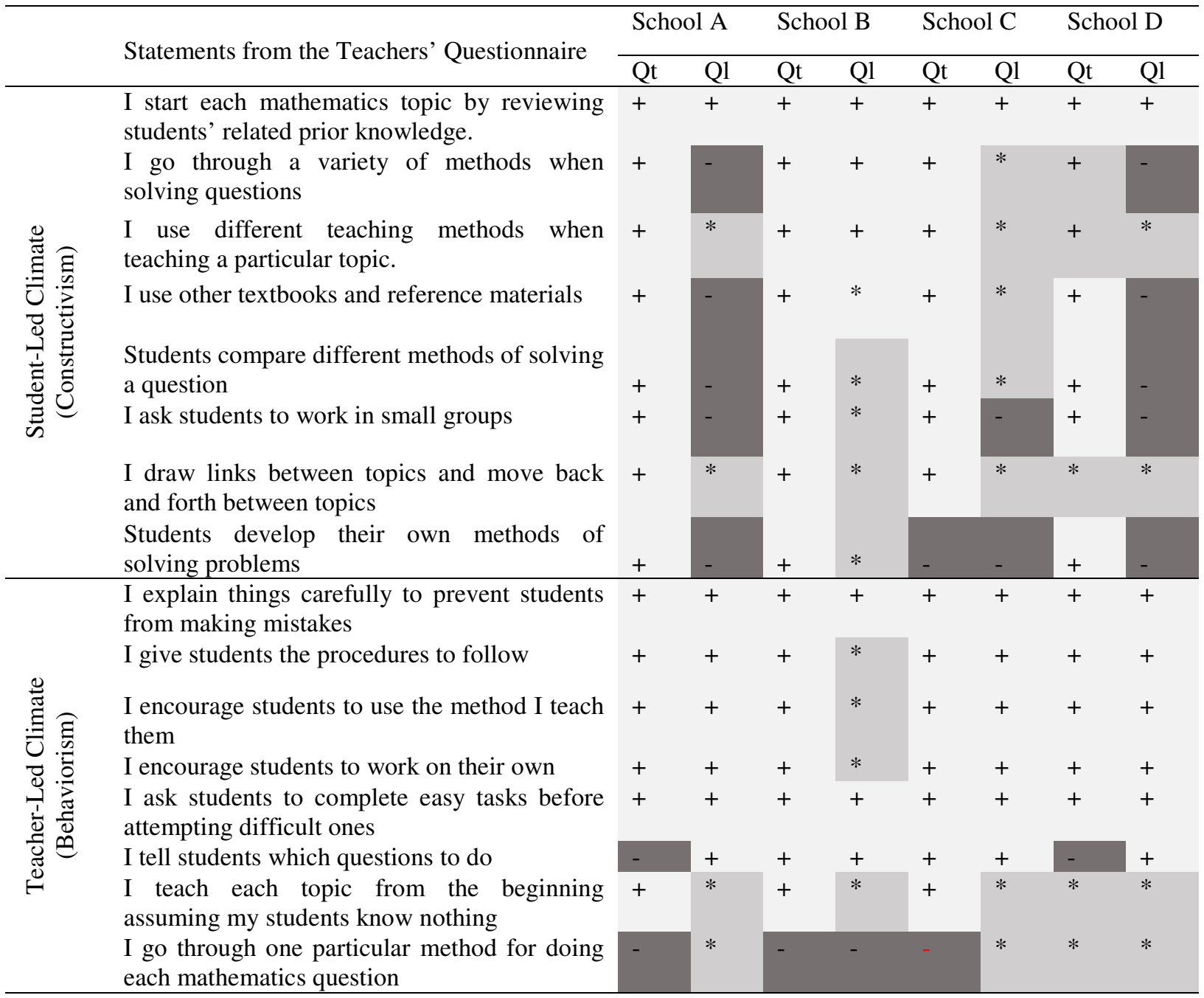

As discussed above, the recommended teaching methods in the mathematics curriculum in Ghana, is the use of co-operative learning where individual students can work with their peers to develop new knowledge and take responsibility of their own learning (MoESS, 2007). The results from the classroom observation revealed that teacher's perception of their teaching regarding encouraging group work was different from what they actually do in their respective classrooms. The classroom observation results from individual lessons revealed that, majority of the students were seen doing individual work in most lessons observed. The only time students' were seen talking to each other was when they were comparing their answers. However, it was interesting to note that, in schools B and C, although teacher-centered approach was mostly used, students' participation was encouraged and stimulated when students were given the opportunity to present and explain their work. Despite this proactive approach by the teachers' in these two schools, only the few students who were found answering questions and actively participating in the teaching-learning process were normally called to explain and discuss their work. This is not consistent with the curriculum guidelines which aim at encouraging all students' to be active participants in the teaching-learning process.

In general, although almost all the teachers' perceived and acknowledge the importance of student-centered 
Ampadu, E.

approach of teaching, as outlined in the new curriculum, their actual teaching differs considerably. Teachers' perceptions of their teaching practices relating to teacher-centered approaches to teaching were more consistent with their actual teaching practices as compared to their perceptions relating to student-centered approach of teaching and this is evident in table 3. The results also established that teachers try to prevent their students from making mistakes by explaining things carefully despite the fact that student's mistakes and misconceptions are part of the teaching-learning process as argued by Willis (2010). There were no difference between teachers' perception of their teaching regarding encouraging students to avoid mistakes and what they actually do in class. This also undermines the principles of encouraging students to develop their own problem solving methods and approaches.

\section{Discussions}

The debate on mathematics teaching and learning has been triggered by the need for a change in instructional practices from a teacher-centered approach to a constructivist approach which is more student-centered as prescribed in the national curriculum. The results from this study show that mathematics teachers' perceptions of their classroom practices are not wholly consistent with what they actually do. This suggests that, as much as teachers are aware of the requirements the national curriculum, the majority of these teachers have not been able to fully conceptualize these ideas and requirements in their classroom discourse. In general, although most of the teachers professed that they used a student-centered approach to teaching; teacher-centered methods were most often used.

The movement towards a more constructivist approach was not fully evident in most of the classrooms observed. The present study therefore argues that, although mathematics teachers may possess in-depth knowledge about the national curriculum requirements and the possible changes, its implementation is problematic. This proposition corroborates the perceptions of the teachers and the results from the classroom observations. The findings provide mathematics teachers with new ideas in encouraging and stimulating students' active participation in the teaching-learning process in fulfilment on the trends in mathematics education and the requirements of the new curriculum.

\subsection{Implications and Recommendations}

Although the present study is limited to only some selected schools and teachers, the findings and results from the study have significant implications for policy makers, teachers and students and the Ministry of Education in general. For policy makers, the results and findings from the study shows that despite the numerous advantages associated with constructivism which is the underlining principle of the new mathematics curriculum, teachers ideologies regarding teaching and learning have not changed that much. It is therefore recommended that there is the need for sensitization workshops for these teachers to understanding the principles of constructivism and its implementation in mathematics classrooms. In addition to this, the findings from this study show some level of inconsistencies between teachers' perceptions of their teaching practices and their actual teaching practices. It is therefore recommended that teacher ought to be innovative in their teaching in order to embrace the principles and requirements of the new curriculum.

\section{References}

Adentunde, I. A. (2007). Improving the teaching and learning of mathematics in second cycle institutions in Ghana. Pakistan Journal of Social Sciences, 4(3), 340-344.

Ampiah, J. G.; Akwesi, C.K; Kutor N. K., \& Brown-Acquaye, H. A. (2000). Perception of teachers, pupils and parents about science and mathematics: STM/JICA project, Report 2. Accra Ghana.

Akyeampong, A. K., \& Kuroda, N. (2007). Improving the Teaching of Science and mathematics in basic schools in Ghana: Challenges and lessons from technical cooperation assistance, In N. Masafum, M. J. Rogan, \& M. C. Magno (Eds.), Mathematics and science in developing countries: Issues, experiences, and 
Implementing a new mathematics curriculum: Mathematics teachers' beliefs and practices

cooperation prospects, University of Philippines Press.

Anamuah-Mensah, J., \& Mereku, D. K. (2005). Ghanaian JSS2 students' abysmal mathematics achievement in TIMMS-2003: A consequence of the basic school mathematics curriculum. Mathematics Connection, 5 , $1-13$.

Anamuah-Mensah, J., Mereku, D. K., \& Asabere- Ameyaw, A. (2004). Ghanaian junior secondary school student's achievement in mathematics and science: Results from Ghana's participation in the 2003 trends in international mathematics and science study. Accra, Ghana.

Asiedu-Addo, S. K. (2004). Mathematics teachers' knowledge of the subject content and methodology, Mathematics Connection, 4, 45-51.

Coffie, O. P. (2004). Mathematics teaching/learning in basic and senior secondary schools.Mathematics Connection, 4, 52-55.

Chambers, P. (2008). Teaching mathematics: Developing as a reflective secondary teacher. Sage, London.

Creswell, J. W., \& Clark L. P. (2007). Designing and conducting mixed methods research. Thousand Oaks, CA: Sage Publications.

Ernest, P. (1989). The impact of beliefs on the teaching of mathematics. In P. Ernest (Ed.), Mathematics teaching: The state of the art (pp. 249-254). London: Falmer Press.

Ernest, P. (1994) (Ed.). Mathematics education and philosophy: An international perspective. London: Falmer Press.

Ernest, P. (2001). Foreword. In S. Goodchild (Ed.), Students goals: A case study of activity in a mathematics classroom (pp. 7-8). Bergen, Norway: Caspar Forlag.

Fletcher, J. A (2005), Constructivism and mathematics education in Ghana, Mathematics Connection, 3, 29-36. Frempong G. (2010). Equity and quality mathematics education with schools: Findings from TIMMS data for Ghana. African Journal of Research in Mathematics, Science and Technology Education, 14(3), 50-62.

Hatch, J. A. (2002). Doing qualitative research in educational settings. Albany: State University of New York Press.

Hersh, R. (1986). Some proposals for revising the philosophy of mathematics, In T.Tymoczko (Ed.), New directions in the philosophy of mathematics (pp. 9-28). Boston: Birkhauser.

Huck, S. W. (2000). Reading statistics and research ( $3^{\text {rd }}$ ed.). New York: Longman.

Jita, L. (2002). A transformative practice in science education: What is it? What does it looks like? Images from South African classrooms. Paper Presented at the Southern Association for Research in Mathematics, Science and Technology Education, Durban.

Jurdak, M. E. (1991). Teachers' conceptions of math education and the foundations of mathematics. In the Proceedings of the 15th international conference for the Psychology of Mathematics Education (PME) (pp. 137-144). Assissi, Italy: PME.

Kislenko, K. (2005). Student's beliefs and attitudes towards mathematics teaching and learning - An introduction to the research in mathematics education: Theoretical and methodological overview, In B. Hudson \& J. Fragner (Eds.), Researching the teaching and learning of mathematics II (pp. 239-252). Washington D.

C: Mathematical Association of Ghana.

Liu, J., \& Li, Y. (2010). Mathematics curriculum reform in the Chinese mainland: Changes and challenges. In F. K. S. Leung \&Y. Li (Eds.), Reforms and issues in school mathematics in East Asia: Sharing and understanding mathematics education policies and practices (pp. 9-32). Rotterdam, Sense Publishers.

Ministry of Education, Science and Sports. (2007). Teaching syllabus for mathematics, Accra, Ghana.

NCTM. (1989). Principles and standards for school mathematics. Reston, VA: Author.

NCTM. (1991). Professional standards for teaching mathematics. Reston, VA: Author.

Pepin, B. (1999). Epistemologies, beliefs and conceptions of mathematics teaching and learning: The theory, and what is manifested in mathematics teachers' work in England, France, and Germany. TNTEE Publications, 2(1), 127-146.

Schoenfeld, A. H. (2002). Research methods in (mathematics) education. In L. English (Ed.), Handbook of international research in mathematics education (pp. 435-487). Mahwah, NJ: Erlbaum.

Schraw, G. J., \& Olafson, J., L. (2008). Assessing teachers' epistemological and ontological worldviews, In M. S. 
Ampadu, E.

Khine (Ed.), Knowing, knowledge and beliefs: Epistemological studies across diverse cultures (pp. 25-44). USA: Springer.

Speer, N. (2005). Issues of methods and theory in the study of mathematics teachers' professed and attributed beliefs. Educational Studies in Mathematics, 58(3), 361-391. http://dx.doi.org/10.1007/s10649-005-2745-0

Speer, N. (2008). Connecting beliefs and practices: A fine-grained analysis of a college mathematics teacher's collections of beliefs and their relationship to his instructional practices. Cognition and Construction, 26(2), 218-267. http://dx.doi.org/10.1080/07370000801980944

Thomasenia, L. A. (2000). Helping students to learn and do mathematics through multiple intelligences and standards for school mathematics. Childhood Education, 77(2), 86-103. http://dx.doi.org/10.1080/00094056.2001.10521636

Willis, J. (2010). Learning to love math: Teaching strategies that change student attitudes and get results. USA: ASCD. 